\title{
Cerebral hemodynamics: concepts of clinical importance
}

\author{
Hemodinâmica encefálica: conceitos de importância clínica \\ Edson Bor-Seng-Shu', William S. Kita², Eberval G. Figueiredo', Wellingson S. Paiva', Erich T. Fonoff', \\ Manoel J. Teixeira ${ }^{1}$, Ronney B. Panerai ${ }^{3}$
}

\begin{abstract}
Cerebral hemodynamics and metabolism are frequently impaired in a wide range of neurological diseases, including traumatic brain injury and stroke, with several pathophysiological mechanisms of injury. The resultant uncoupling of cerebral blood flow and metabolism can trigger secondary brain lesions, particularly in early phases, consequently worsening the patient's outcome. Cerebral blood flow regulation is influenced by blood gas content, blood viscosity, body temperature, cardiac output, altitude, cerebrovascular autoregulation, and neurovascular coupling, mediated by chemical agents such as nitric oxide (NO), carbon monoxide (CO), eicosanoid products, oxygen-derived free radicals, endothelins, $\mathrm{K}^{+}, \mathrm{H}^{+}$, and adenosine. A better understanding of these factors is valuable for the management of neurocritical care patients. The assessment of both cerebral hemodynamics and metabolism in the acute phase of neurocritical care conditions may contribute to a more effective planning of therapeutic strategies for reducing secondary brain lesions. In this review, the authors have discussed concepts of cerebral hemodynamics, considering aspects of clinical importance.
\end{abstract}

Key words: cerebral hemodynamics, cerebral blood flow, cerebral autoregulation, neurovascular coupling, brain injuries, traumatic, subarachnoid hemorrhage.

\section{RESUMO}

Alterações hemodinâmicas e metabólicas do encéfalo ocorrem frequentemente em diversas doenças neurológicas, principalmente em condições de traumatismo cranioencefálico e acidente vascular encefálico, com vários mecanismos patofisiológicos lesionais. 0 desacoplamento resultante do fluxo sanguíneo e do metabolismo encefálico pode resultar em lesões encefálicas secundárias, principalmente nas primeiras fases, e, consequentemente, no agravamento do desfecho neurológico dos pacientes. Diversos fatores influenciam o fluxo sanguíneo encefálico, entre eles, a concentração sanguínea de gases, viscosidade sanguínea, temperatura corpórea, débito cardíaco, altitude, autorregulação cerebrovascular e acoplamento neurovascular, que é mediado por óxido nítrico (ON), monóxido de carbono (CO), eicosanoides, radicais livres derivados do oxigênio, endotelinas, potássio, íons hidrogênio e adenosinas. Melhor compreensão destes fatores é fundamental para o manejo clínico dos pacientes neurológicos críticos. A avaliação hemodinâmica e metabólica do encéfalo nas lesões encefálicas agudas pode contribuir para o planejamento de estratégias de redução das lesões encefálicas secundárias. Nesta revisão, os autores discutiram princípios da hemodinâmica encefálica, considerando os aspectos de importância clínica.

Palavras-Chave: hemodinâmica cerebral, fluxo sanguíneo cerebral, autorregulação cerebral, acoplamento neurovascular, traumatismo encefálico, hemorragia subaracnóidea.

Head trauma and stroke are conditions typically associated with impaired cerebral blood flow (CBF) and metabolism, although some pathophysiologic mechanisms may differ between them ${ }^{1-4}$. Impairments in the CBF and metabolism can lead to secondary brain injuries, particularly in the early weeks, consequently worsening the clinical outcome ${ }^{5-6}$. Assessment of both cerebral hemodynamics and metabolism in the acute phase of these conditions may contribute to a more effective planning of therapeutic strategies for reducing secondary brain lesions?
The objective of this review was to address concepts of cerebral hemodynamics, considering aspects of clinical importance.

\section{NORMAL CBF}

The human brain represents approximately $2 \%$ of total body weight, yet it receives approximately $20 \%$ of cardiac output and uses $20 \%$ of total body oxygen consumed under normal conditions. In this situation, most of the energy of the brain is obtained exclusively from aerobic metabolic process.

${ }^{1}$ Division of Neurological Surgery, Hospital das Clínicas, University of São Paulo School of Medicine, São Paulo SP, Brazil;

${ }^{2}$ Faculty of Medicine of Marília, São Paulo SP, Brazil;

${ }^{3}$ Department of Cardiovascular Sciences, University of Leicester, Leicester, UK.

Correspondence: Edson Bor-Seng-Shu; Division of Neurological Surgery, Hospital das Clínicas, USP; Avenida Doutor Enéas de Carvalho Aguiar 255;

05403-000 São Paulo SP - Brasil; E-mail: edsonshu@hotmail.com

Conflict of interest: There is no conflict of interest to declare.

Received 18 November 2011; Received in final form 29 November 2011; Accepted 06 December 2011 
Therefore, impairment in the supply of nutrients and oxygen to the brain can cause cellular damage.

$\mathrm{CBF}$ varies directly with cerebral perfusion pressure (CPP), which is defined as the difference between mean arterial and intracranial pressures, and inversely with cerebrovascular resistance (the sum of vascular resistance to flow, particularly at the level of the small pial arteries and penetrating pre-capillary arterioles). The contribution of any given cerebral vessel to overall CBF is defined by factors, such as its radius and length, and both blood viscosity and pressure.

Tissue perfusion in the brain is approximately 50 to $55 \mathrm{~mL} / 100 \mathrm{~g} / \mathrm{min}$. As blood perfusion is progressively reduced, oxygen extraction from hemoglobin, which is indicated by arteriovenous difference in oxygen, increases without clinical manifestation. When blood perfusion reaches 25 to $30 \mathrm{~mL} / 100 \mathrm{~g} / \mathrm{min}$., electroencephalographic (EEG) abnormalities and consciousness alterations may occur. As blood perfusion falls further to below approximately $20 \mathrm{~mL} / 100 \mathrm{~g} / \mathrm{min}$., EEG becomes isoelectric and neurons increasingly switch to anaerobic metabolism, with concomitant increased production of lactate and hydrogen ions. Once perfusion reaches 10 to $12 \mathrm{~mL} / 100 \mathrm{~g} / \mathrm{min}$., neurotransmission is lost, sodium-potassium pumps fail and cytotoxic edema ensues. In the absence of cerebral hypothermia, perfusion of less than 6 to $10 \mathrm{~mL} / 100 \mathrm{~g} / \mathrm{min}$. triggers tissue death cascade mediated by calcium and glutamate $^{8}$. These data emphasize the importance of CBF assessments in neurocritical patients: no clinical signs are associated with low CBF until its values have reached the threshold of functional neuronal impairment, which is close to the one of permanent neuronal injury. Therefore, early recognition of low CBF states can help identifying and treating patients before the occurrence of ischemic brain lesions.

\section{CBF REGULATION}

\section{Cerebral autoregulation}

Cerebral or pressure autoregulation is the inherent ability of blood vessels to keep CBF relatively constant over a wide range of arterial blood pressure (ABP) levels by the interplay of numerous physiological mechanisms.

A sudden change in mean $\mathrm{ABP}$ leads to a simultaneous change in CBF initially, but it also triggers a number of other responses. For instance, ABP augmentation produces dilatation of cerebral arteries, which leads to a chain of events: changes in smooth muscle ionic permeability, muscle contraction, vessel narrowing, and increase in cerebrovascular resistance (myogenic mechanism). Concomitantly, CBF elevation due to $A B P$ augmentation causes both increase in tissue $\mathrm{O}_{2}$ and decrease in the concentration of $\mathrm{CO}_{2}$ and other products of cerebral metabolism. In the absence of greater demand for $\mathrm{O}_{2}$, a complex sequence of events restores the balance between $\mathrm{O}_{2}$ supply and demand by means of vasoconstriction mediated by activation of nitric oxide (NO) and other metabolites in the arterial endothelium (metabolic mechanism). Recently, sympathetic neural control has been implicated as one of the mechanisms of cerebral autoregulation (neurogenic mechanism) 9

The basic concept of cerebral autoregulation usually involves either the static or dynamic relationship between $A B P$, or CPP, and CBF. In the assessment of static cerebral autoregulation, $\mathrm{CBF}$ (or CBF velocity) is first measured at a constant baseline ABP (or CPP), followed by another steady state CBF (or CBF velocity) measurement after pharmacological manipulation of ABP. If static cerebral autoregulation is preserved, mean $\mathrm{CBF}$ (or $\mathrm{CBF}$ velocity) is expected to remain constant, despite changes in $\mathrm{ABP}$ (or $\mathrm{CPP}$ ) that in most cases lie in the 60 to $150 \mathrm{mmHg}$ range. In the absence of a constant CBF, cerebral autoregulation is considered impaired. The concept of dynamic cerebral autoregulation is based on the temporal response of autoregulatory mechanisms promoting fast restoration of CBF to its original value. This response normally occurs within two to ten seconds upon CBF disturbance by a sudden change in ABP. Measurement of dynamic cerebral autoregulation offers the advantage of investigating beat-tobeat variations of pressure-flow in cerebral circulation and of differentiating response time of the mechanism ${ }^{2,9}$. Dynamic cerebral autoregulation may be assessed by comparing continuous measurements of cerebral blood velocity with simultaneous measurements of spontaneous fluctuations in ABP.

The lower and upper limits of static pressure autoregulation (usually in the 60 to $150 \mathrm{mmHg}$ range) are variable and can be influenced by a number of factors, such as: hematocrit and hemoglobin concentration, blood levels of $\mathrm{CO}_{2}, \mathrm{O}_{2}$, and $\mathrm{H}^{+}$, brain temperature, cardiac output, and altitude (Fig 1). In chronic hypertension, values for lower and upper limits

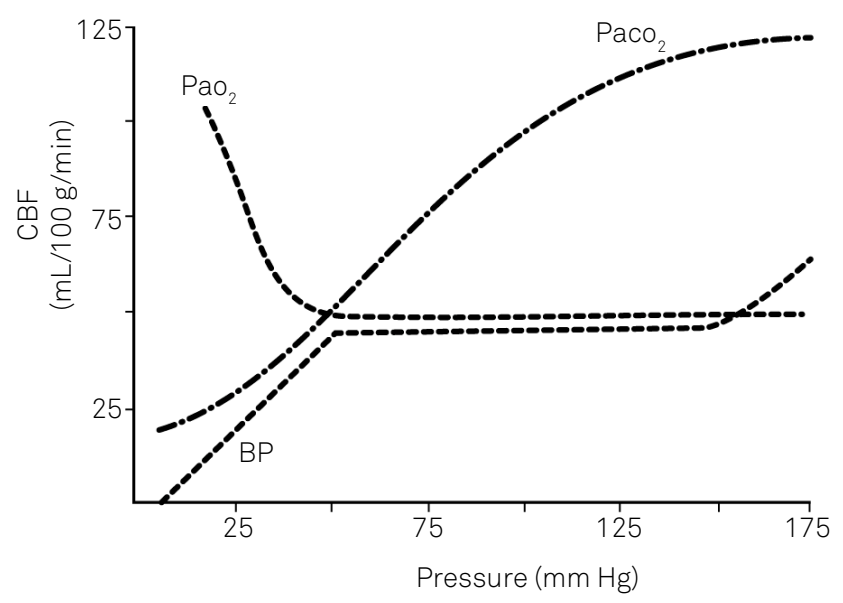

CBF: cerebral blood flow.

Fig 1. Cerebrovascular autoregulation in health and effect of blood gases on the CBF. Influence of alterations in arterial blood gases and blood pressure on cerebral blood flow. Acute hypoxia triggers dilation of cerebral microcirculation and increase in CBF. Hypercapnia causes marked dilation of cerebral arterioles and CBF elevation, whereas hypocapnia causes vasoconstriction and decrease in CBF. 
of pressure autoregulation are higher than those under normal conditions, resulting in a degree of resetting as high as $40 \mathrm{mmHg}$ (Fig 2). Therefore, acceptable ABP levels for healthy subjects may be associated with lower CBF. During hypercapnia, cerebral vessels are dilated and have reduced capacity to further dilate in response to reductions in perfusion pressure $^{10}$. The control of the aforementioned factors is important in order to avoid aggravation of cerebral autoregulation capacity, thereby preventing secondary cerebral lesions.

Hypoxia, ischemia, intracranial hypertension, traumatic brain injury (TBI), stroke, renal and hepatic failures, as well as sepsis can impair cerebral pressure autoregulation. Once the autoregulatory mechanisms have been abolished, CBF passively follows changes in ABP and impaired cerebral pressure (ICP). Under these conditions, the brain becomes vulnerable to ischemic or hyperemic injuries if perfusion pressure does not remain coupled with metabolic demands (Fig 2). In the TBI, patients with disturbed cerebral autoregulation, recommended CPP (greater than $70 \mathrm{mmHg}$ ) can be associated with severe cerebral hyperemia, predisposing the brain to hemorrhages, swelling, and intracranial hypertension. Thus, recent guidelines have suggested lower CPP levels for this patient group $(60 \mathrm{mmHg})^{11}$. A recent study has demonstrated that $\mathrm{CPP}<50 \mathrm{mmHg}$ and $\mathrm{CPP}<60 \mathrm{mmHg}$ were associated with favorable outcomes, whereas $\mathrm{CPP}>70 \mathrm{mmHg}$ and $\mathrm{CPP}>80$ $\mathrm{mmHg}$ were associated with unfavorable outcomes in TBI patients with impaired cerebral pressure autoregulation ${ }^{12}$.

\section{Neurovascular coupling}

Increased cerebral functional activity is accompanied by rapid increases in oxygen utilization, glucose uptake and metabolism, as well as blood flow in the activated brain areas ${ }^{13,14}$.

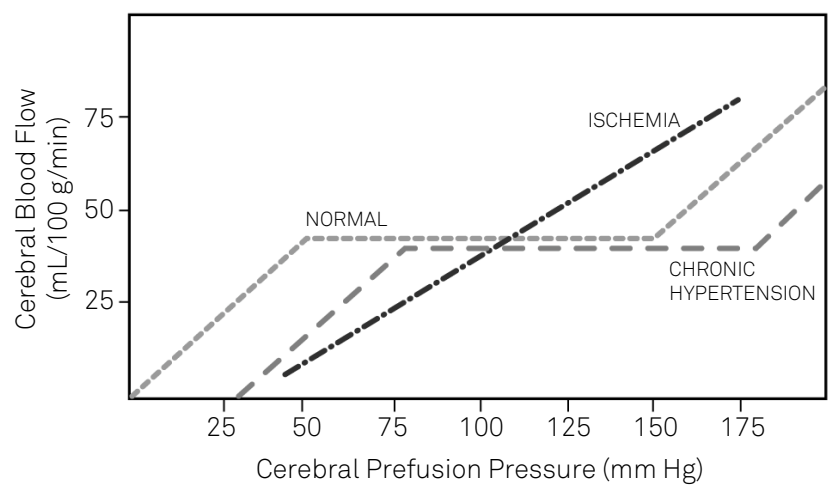

CBF: cerebral blood flow.

Fig 2. Cerebrovascular autoregulation in health, chronic hypertension and during autoregulation loss. In chronic hypertension, values for lower and upper limits of pressure autoregulation are higher than those under normal conditions, resulting in a degree of resetting as high as 40 $\mathrm{mmHg}$. Therefore, acceptable ABP levels for healthy subjects may be associated with lower CBF. Ischemia can impair cerebral autoregulation allowing CBF to vary directly with blood pressure leading to brain lesion.
Flow-metabolism coupling in the brain is mediated by chemical agents involved in electrical and biochemical interactions among neurons, astrocytes, endothelium cells, and smooth muscle cells. The main chemical agents such as NO, carbon monoxide (CO), eicosanoids products, oxygenderived free radicals, endothelins, $\mathrm{K}^{+}, \mathrm{H}^{+}$, and adenosines are presented as the following topics (Fig 3).

\section{Hydrogen ions}

The diameter of cerebral blood vessels, which influences CBF, is highly dependent on tissue proton $\left(\mathrm{H}^{+}\right)$ concentration $^{15,16}$. Hypercapnic and normocapnic acidosis have been shown to cause dilation in cerebral blood vessels, and consequently increased $\mathrm{CBF}^{17}$. In rats, a stepwise increase
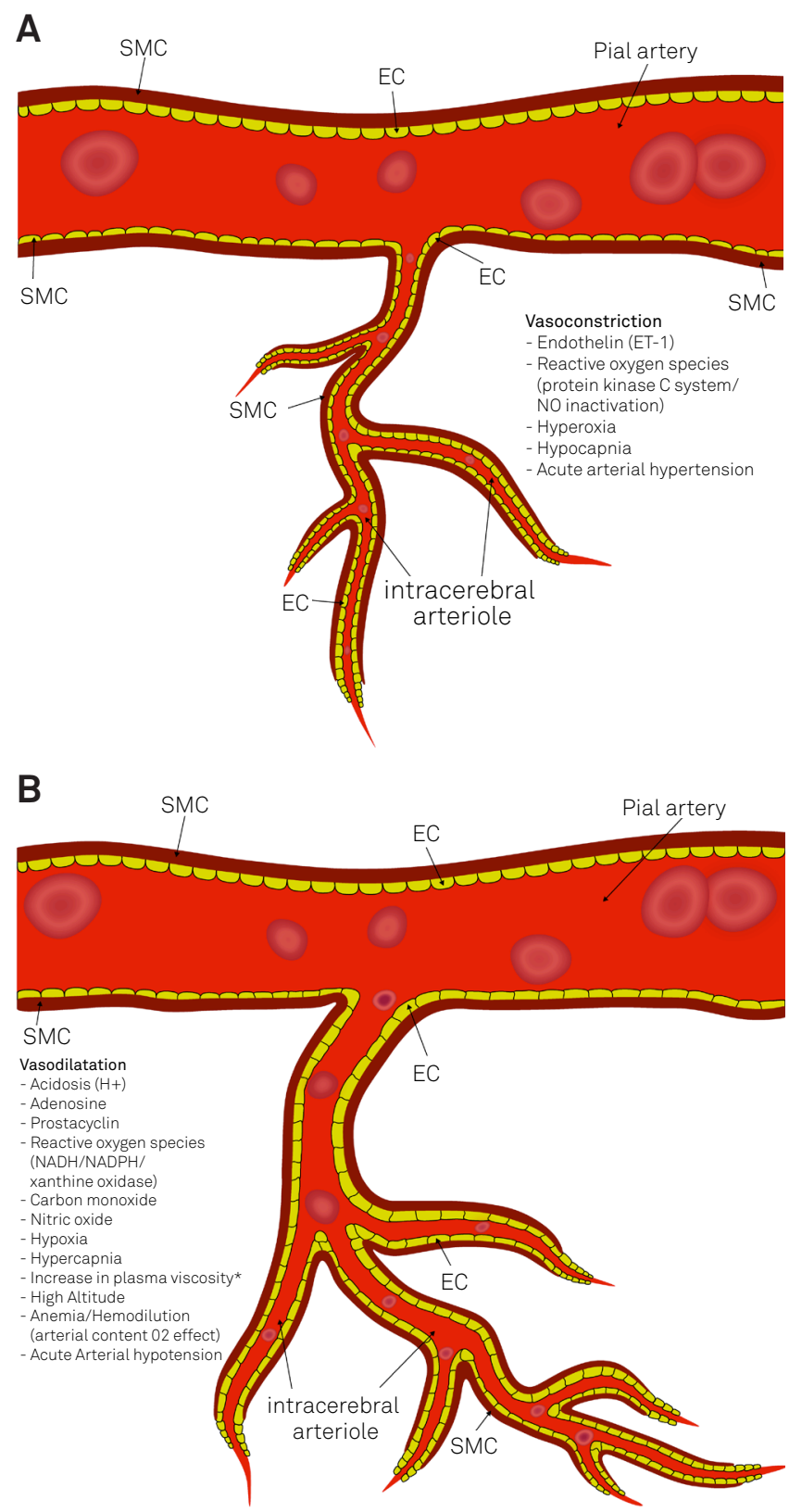

SMC: smooth muscle cell; EC: edothelium cells.

Fig 3. (A) factors that can induce vasoconstriction; (B) factors that can induce vasodilation. 
of extraluminal proton concentration from $\mathrm{pH} 7.4$ to 7.0 led to a linear increase in the cerebral vessel diameter ${ }^{18}$. Maximum dilation was reached at a $\mathrm{pH}$ of 7.0 with no further diameter increase upon lowering of $\mathrm{pH}$ to 6.0. The mechanism of acidosis-induced dilation consists of activation of $\mathrm{K}_{\text {ATP }}$ and $\mathrm{K}_{\mathrm{Ca}}$ channels in response to increased extraluminal proton concentration. Moreover, cerebral artery dilatation during moderate elevations in proton concentration is highly dependent on the basal perivascular NO level, whereas at lower extraluminal pH (7.0) vasodilation becomes independent of NO and it is probably mediated by other mechanisms ${ }^{15,16,19}$. In contrast, the infusion of $8.4 \%$ sodium bicarbonate in TBI patients can decrease ICP, without generating metabolic acidosis ${ }^{20}$.

\section{Adenosine}

Adenosine is a purine nucleoside that regulates $\mathrm{CBF}$ and modulates neuronal and synaptic activity ${ }^{21,22}$. During neuronal activity, seizures, hypoxia, and ischemia, the adenosine level increases in cerebrospinal fluid. Adenosine results from the breakdown of AMP, a product derived from ATP and ADP hydrolysis during increased neuronal activity. This neurotransmitter acts through two classes of purinergic receptors, A1 and $\mathrm{A} 2{ }^{21}$. A1 receptors are found in neurons and they are coupled to $G_{i / o}$ proteins, which inhibit and decrease neuronal excitability. A2 receptors seem to be present in both smooth muscle and endothelial cells of cerebral blood vessels and induce vasodilatation by releasing endogenous factors, such as prostacyclin, nitric oxide, endothelium derived hyperpolarizing factor, epoxyeicosatrienoic acids, and reactive oxygen species ${ }^{21}$. Furthermore, in a variety of circulatory beds, studies have documented that vasodilatation by adenosine occurs by means of a direct interaction with adenosine receptors located on the vascular smooth muscle. The effects of caffeine on cerebral circulation can be attributed to its inhibitory effects on adenosine receptors ${ }^{23}$.

\section{Endothelins}

Endothelin-1 (ET-1) is a 21 amino acid bioactive peptide, which is predominantly synthesized and released by endothelial cells and is a potent vasoconstrictor implicated in the pathogenesis of vasospasm and delayed cerebral ischemia in aneurysmal subarachnoid hemorrhage (SAH) patients. ET-1 is not only generated by vascular-endothelial and smoothmuscle cells, but also by neurons, astrocytes, and monocytes. Hemoglobin stimulates monocytes ET-mRNA expression, a mechanism that increases ET-1 concentration in the cerebrospinal fluid in SAH. Selective antagonists of the two ET-1 receptors (ETA and ETB) have been used for SAH-induced vasospasm in animal models, where vasospasm can be limited by blocking the detrimental effects of endogenous ET-124,25. ET-1 has been reported to be released from astrocytes after hypoxia. Moreover, it has been speculated that ET-1 released from neuronal and glial cells after early ischemic damage may later contribute to delayed cerebral ischemia ${ }^{24}$.
In animal models of TBI, brain ET-1 concentrations increase two- to three-fold, and they are associated with prolonged vasoconstriction and brain injury due to their high potency and long duration of action. Antagonists of ET-1 can reverse this vasoconstrictor response ${ }^{26}$.

\section{Prostacyclin}

Prostacyclin is a metabolite of arachidonic acid that is produced with other prostaglandins and thromboxanes by two cyclooxygenase (COX) enzymes, COX-1 and COX-227. COX-2 is expressed primarily in macrophages, fibroblasts, endothelium, vascular muscle, and constitutively in the brain. Lipopolysaccharide, adenosine 3', 5'-cyclic monophosphate (cAMP), hypoxia, inflammatory cytokines, growth factors, and hormones stimulate the expression of COX-2. Prostacyclin and analogs produce relaxation of cerebral arteries in vitro and in vivo mediated by an endothelium-independent mechanism, NO formation, potassium channels, and activation of adelynate cyclase ${ }^{28}$. Prostacyclin may reduce vasoconstriction elicited by $\mathrm{SAH}^{29}$. Beneficial effects of low-dose prostacyclin infusion have been reported in severe traumatic brain injury ${ }^{30}$.

\section{Reactive oxygen species}

Reactive oxygen species have multiple effects on vascular cells. Oxygen-derived free radicals, such as the superoxide (superoxide anion) and hydroxyl radicals, are a subgroup of reactive oxygen species that contain one or more unpaired electrons. Superoxide dilates cerebral arterioles when generating $\mathrm{NADH}$ or NADPH by xanthine oxidase, mediated by potassium channels ${ }^{31-33}$. Reactive oxygen species play a role in the pathophysiology of cerebral vasospasm through activation of the protein kinase $\mathrm{C}$ system and/or inactivation of NO. In experimental models, NADPH oxidase inhibitor attenuated SAH cerebral vasospasm ${ }^{34}$.

\section{CO}

$\mathrm{CO}$ is produced endogenously in the endothelium during enzymatic degradation of heme by means of heme oxygenase (HO). CO is a potent vasodilator of cerebral arterioles in vivo and contributes to cerebrovascular dilation induced by hypoxia and excitatory amino acids. The dilator actions of $\mathrm{CO}$ involve both prostacyclin and NO as permissive enablers, because prostacyclin and NO provide the background cGMP/PKG activity needed to allow $\mathrm{CO}$ to dilate pial arterioles via activation of $\mathrm{Ca}^{2+}$ channels mediated by $\mathrm{K}^{+}$and hyperpolarization of vascular smooth muscle cell. Considering the interaction between the mechanism of $\mathrm{CO}$ and $\mathrm{NO}$ production and given that $\mathrm{NO}$ provokes greater vasodilatory response than $\mathrm{CO}$, one gas can interfere with the vasodilation response of the other ${ }^{35-37}$.

$\mathrm{SAH}$ and focal ischemia can stimulate $\mathrm{CO}$ overproduction by inducing HO-1 and heme augmentation. However, the precise actions of this gas under these pathologic circumstances warrant further investigation ${ }^{36}$. 
NO

NO is an inorganic labile gaseous molecule, which is released from endothelial cells and perivascular nitrergic neurons ${ }^{38}$. It results in cerebral vasodilatation, decrease in cerebrovascular resistance and increase in CBF. Endothelial NO also acts as an antiplatelet, antithrombotic, antiproliferative, and antiatherosclerotic agent ${ }^{38}$. Therefore, endothelial dysfunction and nitrergic neuronal impairment lead to cerebral circulatory disorders. The vasodilatory effect of NO in the vascular muscle is mediated by potassium channels and soluble guanylate cyclase, raising intracellular concentration of cGMP $\mathrm{CM}^{39,40}$. Relaxation of cerebral vessels in response to acetylcholine, bradykinin, vasopressin, oxytocin, substance P, histamine, sodium fluoride, endothelin, ADP, and ATP are dependent on NO production.

According to the two-stage hypothesis for delayed cerebral vasospasm ${ }^{39}$, NO-releasing neurons are injured by oxyhemoglobin (oxyHb), leading to reduced availability of NO in vessel wall and vasoconstriction (Phase I). Increased shear stress evoked by narrowing of the arterial lumen can stimulate endothelial NO synthase (eNOS). Hemoglobin breakdown to bilirubin oxidized fragments (BOXes) increases asymmetric dimethylarginine (ADMA), an endogenous inhibitor of eNOS, in the vicinity of cerebral arteries thus further decreasing NO availability and sustaining vasospasm (Phase II). In Phase III (resolution of vasospasm), elimination of BOXes increases NO production by eNOS, resulting in the recovery of dilatory activity of endothelium. This hypothesis suggests that the treatment of delayed cerebral vasospasm should focus on preventing oxyHb neurotoxicity, inhibiting BOX production and exogenous NO delivery.

\section{Potassium ions and channels}

The membrane potential of arterial smooth muscle cell (SMC) is a determinant of vascular tone and is regulated by $\mathrm{K}^{+}$ channels. Opening of $\mathrm{K}^{+}$channels in vascular SMC membranes allows $\mathrm{K}^{+}$to flow out of the cell, resulting in membrane hyperpolarization, whereas inhibition of $\mathrm{K}^{+}$channels results in membrane depolarization. $\mathrm{K}^{+}$channel-mediated membrane hyperpolarization closes voltage-dependent $\mathrm{Ca}^{2+}$ channels, which decreases $\mathrm{Ca}^{2+}$ entry and leads to vasodilation, while membrane potential depolarization causes vasoconstriction ${ }^{41}$.

Four different subtypes of $\mathrm{K}^{+}$channels can be identified in the arterial SMC: inward rectifier $\mathrm{K}^{+}\left(\mathrm{K}_{\mathrm{ir}}\right)$ channels, $\mathrm{Ca}^{2+}$ - sensitive $\mathrm{K}^{+}(\mathrm{BK})$ channels, voltage-dependent $\mathrm{K}^{+}\left(\mathrm{K}_{\mathrm{V}}\right)$ channels, and ATP-sensitive $\mathrm{K}^{+}\left(\mathrm{K}_{\text {ATP }}\right)$ channels ${ }^{41}$. The expression profile and functional contribution of each subtype vary according to the tissue type and caliber of the arterial segment.

Neuronal activation and astrocyte modulation have the potential to generate vasoconstriction and vasodilatation mediated by $\mathrm{K}^{+}$channels and membrane potential variations, according to extracellular potassium concentration. Potassium channel activator cromakalim has been shown to limit the severity of cerebral vasospasm if administered 24 hours after SAH in experimental models ${ }^{42}$.

\section{Effect of arterial blood gases}

\section{Oxygen}

The brain has a high metabolic demand for oxygen. Acute hypoxia triggers dilation of cerebral microcirculation and increase in CBF (Fig 1) ${ }^{43}$. In general, CBF does not change substantially until tissue $\mathrm{PO}_{2}$ falls below $50 \mathrm{mmHg}{ }^{43}$. As hypoxia decreases $\mathrm{P}_{\mathrm{O} 2}$ further, $\mathrm{CBF}$ can rise to $400 \%$ of resting levels ${ }^{44}$. Increases in $\mathrm{CBF}$ do not change metabolism but cause hemoglobin saturation to fall from $100 \%$ at $\mathrm{P}_{\mathrm{O} 2}>70 \mathrm{mmHg}$ to $50 \%$ at $\mathrm{P}_{\mathrm{O} 2}<50 \mathrm{mmHg}^{44}$. Acute hypoxia can cause an increase in the CBF by means of direct effects on cerebral arterioles. A hypoxia-induced decrease in ATP levels opens $\mathrm{K}_{\text {ATP }}$ channels in arteriole smooth muscle inducing hyperpolarization and vasodilation. Moreover, hypoxia rapidly increases NO and adenosine production resulting in vasodilation ${ }^{45}$.

Recent medical literature reports that impaired cerebral mitochondrial function can occur after TBI. In patients with clinically-defined ischemia, increased cerebral oxygenation or a decrease in arteriovenous $\mathrm{O}_{2}$ difference, the presence of decreased $\mathrm{O}_{2}$ metabolism due to mitochondrial dysfunction should be suspected ${ }^{46}$.

\section{Carbon dioxide}

Hypercapnia causes marked dilation of cerebral arterioles and CBF elevation, whereas hypocapnia causes vasoconstriction and decrease in $\mathrm{CBF}$ (Fig 1$)^{45}$. In humans, $5 \% \mathrm{CO}_{2}$ inhalation leads to a $50 \%$ rise in $\mathrm{CBF}$ and $7 \% \mathrm{CO}_{2}$ inhalation causes a $100 \%$ increase in $\mathrm{CBF}^{45}$. The mechanism of hypercapnic vasodilation appears to involve a direct effect of extracellular $\mathrm{H}^{+}$ on vascular smooth muscle ${ }^{45}$. This is supported by findings that neither bicarbonate ion nor changes in $\mathrm{P}_{\mathrm{CO} 2}$ alone affect the cerebral arteriole diameter ${ }^{45}$. Hypercapnia can increase $\mathrm{CBF}$, cerebral blood volume and intracranial pressure in addition to impairing cerebral autoregulation ${ }^{47}$. On the other hand, hyperventilation-induced hypocapnia can decrease CBF, cerebral blood volume and ICP due to cerebral vasoconstriction and it has been used in clinical practice to control intracranial hypertension. Although contested by a number of authors, there is increasing evidence that hyperventilation produces cerebral hypoperfusion, decreased cerebral oxygenation, activation of anaerobic cell respiration, and poorer patient outcomes ${ }^{45}$. Furthermore, impaired $\mathrm{CO}_{2}$ cerebrovascular reactivity reflects loss of microvascular function and can be associated with increased risk of cerebral infarction in patients with carotid occlusive disease $\mathrm{e}^{48,49}$.

\section{Blood viscosity and hemodilution effect}

Blood viscosity is an important factor determining blood flow, which depends on hematocrit, erythrocyte aggregability, and plasma viscosity ${ }^{50}$. Changes in arteriolar diameter associated with variation in blood viscosity have been referred to as viscosity autoregulation. This mechanism is analogous to pressure-induced autoregulation and renders the flow behavior 
different to that expected in rigid tubes, in which pressure remains constant and $\mathrm{CBF}$ increases as blood viscosity is reduced. Factors influencing viscosity autoregulation include endothelial wall shear stress and oxygenation. In hemodilution, blood viscosity reduction accounts for approximately half of the increase in $\mathrm{CBF}$, with the remainder caused by the change in arterial content of $\mathrm{O}_{2}$. In an experimental model, a reduction of hematocrit from 32 to $18 \%$ resulted in dilation of pial arterioles and increase in $\mathrm{CBF}$ to maintain cerebral $\mathrm{O}_{2}$ transport ${ }^{51}$.

In microcirculatory paralysis, in which microcirculation is significantly dilated, an increase in viscosity leads to lower $\mathrm{CBF}$. Failure to maintain constant $\mathrm{CBF}$ with increased viscosity during high-flow conditions may be caused by failure of further dilation of cerebral arterioles ${ }^{52}$.

In SAH patients, anemia can worsen the patient's outcome because it may lead to cerebral ischemia by reducing oxygen availability in brain tissue $\mathrm{e}^{53,54}$. Clinical studies suggest that hemoglobin concentrations greater than $11 \mathrm{~g} / \mathrm{dL}$ may be associated with improved SAH outcomes ${ }^{55,56}$. On the other hand, although high hemoglobin concentrations increase blood viscosity resulting in a tendency for autoregulatory vasodilatation, there is an increase in $\mathrm{O}_{2}$ tissue concentration leading predominantly to vasoconstriction and decreased CBF. In patients with anemia, red blood cell transfusion has also been associated with organ dysfunction and increased mortality ${ }^{57,58}$, mediated by inflammatory substances or altered NO metabolism among other factors, predisposing to vasospasm.

Experimental evidence links anemia to reduced brain tissue oxygen pressure and increased neuron injury after acute brain injury ${ }^{59}$. In normal brain, compensatory vasodilation occurs at hemoglobin concentrations lower than $10 \mathrm{~g} / \mathrm{dL}^{60}$. The manifestation of brain hypoxia usually occurs at even lower hemoglobin levels (e.g., $<6$ g/dL) ${ }^{61}$. However, when cerebrovascular reserve is impaired, tissue hypoxia and cell injury may develop at higher hemoglobin concentrations. There are good theoretical reasons to maintain higher hemoglobin concentration after brain injury, since the brain has stringent $\mathrm{O}_{2}$ requirements. Most neurosurgeons prefer a hemoglobin concentration greater than $10 \mathrm{~g} / \mathrm{dL}$ for patients with acute brain injury, in order to maintain optimal oxygen carrying capacity ${ }^{62}$.

\section{Body temperature effect}

In the injured brain, hyperthermia increases metabolic expenditure, blood flow, glutamate-induced neurotoxicity, neutrophil activity, and reactive oxygen species ${ }^{63}$. These events may further enhance the vulnerability of the brain to secondary pathogenic events, thereby exacerbating brain swelling and neuronal damage ${ }^{64}$. Glucose utilization in most regions of the brain changes by approximately 5 to $10 \%$ for every degree Celsius change in body temperature, underscoring the importance of preventing hyperthermia in the acute phase of severe brain injury.
Hypothermia has been proved to induce: a decrease in the rate of brain metabolism, preserving cellular energy stores and aerobic metabolism; a lower release of excitatory neurotransmitters and NO; and a protection of the blood-brain barrier, and a decrease in free radical production ${ }^{65-67}$.

In traumatic brain injury, hypothermia was found to effectively lower elevated ICP, probably by decreasing CBF and the inflammatory response ${ }^{64,68,69}$. Clinical TBI studies have reported the beneficial effects of therapeutic hypothermia on secondary brain injuries and outcomes. Interestingly, mean $\mathrm{CBF}$ in patients with a brain temperature of 36.0 to $37.5^{\circ} \mathrm{C}$ was $37.8 \pm 14.0 \mathrm{~mL} / 100 \mathrm{~g} / \mathrm{min}$. Lowest $\mathrm{CBF}$ was measured in patients with a brain temperature of $<36.0^{\circ} \mathrm{C}(17.1 \pm 14.0 \mathrm{~mL} / 100 \mathrm{~g} / \mathrm{min}$.). A positive trend toward improved outcome was seen in patients with mild hypothermia $\left(35.3 \pm 0.5^{\circ} \mathrm{C}\right)^{70}$.

In $\mathrm{SAH}$, hypothermia has been shown to preserve cerebral autoregulation, reduce cytotoxic edema, limit metabolic alterations and inhibit acute vasospasm, during the acute phase of massive SAH in animal models ${ }^{66}$. The potentially beneficial influence of hypothermia on cerebral blood flow and metabolism in this crucial phase is practicable and might hold the key to further improve the outcome in SAH.

In mild to moderate hypothermia, decreases in CBF are expected to be associated with a slowing down of the cerebral metabolism ${ }^{71}$. However, hypothermia effects on cerebral vascular tone and flow remain a topic of debate, where both increase cerebral vascular tone with reduced CBF as well as hypothermia-induced vasodilation with increased $\mathrm{CBF}^{67}$. Interestingly, neurovascular and neurometabolic coupling was found to be preserved during hypothermia in experimental studies ${ }^{72,73}$.

\section{Cardiac output effect}

There is a linear relationship between CBF velocity and cardiac output at rest and during exercise, as demonstrated under conditions of decreased and increased cardiac output by lower-body negative pressure and infusion of albumin, respectively ${ }^{74}$. Changing postural positions from supine to standing can also reduce cardiac output and, consequently, CBF velocity ${ }^{75}$. Interestingly, decreased CBF velocity was confirmed even though mean arterial pressure was increased. This is possible due to the fact that the lowering of cardiac output can be accompanied by increases in arterial pressure. Therefore, in clinical practice, blood pressure augmentation may not necessarily imply an associated increase in $\mathrm{CBF}^{76}$. The dependence of $\mathrm{CBF}$ on cardiac output is also seen in cardiac patients, in which decreased cerebral oxygenation during exercise can be noted in cardiac patients with decreased perfusion as a result of compromised cardiac output ${ }^{77}$. In SAH patients, left ventricular dysfunction and low cardiac output increase the risk of cerebral infarction associated with vasospasm ${ }^{18,49}$. 


\section{High altitude effect}

The mechanisms underlying the regulation of CBF during acute exposure to high altitude are complex and depend partly on the degree of hypoxic stimulus and on the cerebrovascular sensitivity to hypoxia and $\mathrm{CO}_{2}{ }^{78}$. Upon initial arrival (days two to four) at high altitude (5050 m), CBF velocity can rise by up to $31 \%$ of values measured at sea level, returning to sea-level base values by days seven to nine ${ }^{79}$.

Neurological disorders associated with altitude have an intimate relationship with disturbances of cerebrovascular regulation due to high altitude and with the process of acclimatization. Subjects exposed to hypoxia at high altitudes develop an increase in steady-state CBF velocity associated with impairment of cerebral autoregulation ${ }^{80}$. This phenomenon has been correlated with the risk of developing acute mountain sickness and high-altitude cerebral edema ${ }^{80,81}$.
Therefore, in theory, patients with intracranial hematomas or some degree of brain swelling, irrespective of etiology, can develop or experience worsening intracranial hypertension when transferred to high-altitude locations.

\section{FINAL REMARKS}

Cerebral circulatory abnormalities are frequently found in clinical practice and can lead to secondary cerebral lesions $^{82,83}$. A number of factors can influence CBF and its regulation (Fig $3 \mathrm{~A}$ and $3 \mathrm{~B}$ ). Both the monitoring and control of these factors can help adjust CBF to match cerebral metabolic demands. A deeper understanding of $\mathrm{CBF}$ regulation in brain pathophysiology allows physicians to attain more favorable patients' outcome.

\section{References}

1. Abbas AK, Kumar V, Mitchell RN. Robbins \& Cotran, Patologia, Bases patológicas das doenças. $7^{\text {th }}$ Ed. Brasil: Elsevier; 2005.

2. Aries MJ, Elting JW, De Keyser J, Kremer BP, Vroomen PC. Cerebral autoregulation in stroke: a review of transcranial doppler studies. Stroke 2010;41:2697-2704.

3. Bramlett HM, Dietrich WD. Pathophysiology of cerebral ischemia and brain trauma: similarities and differences. J Cereb Blood Flow Metab 2004:24:133-150.

4. Dogerstein C, Martin NA. Cerebral blood flow in clinical neurosurgery. Youmans neurological surgery. $4^{\text {th }}$ Ed. Philadelphia: Saunders; 2004:519-559.

5. Coles JP, Fryer TD, Smielewski P, et al. Incidence and mechanisms of cerebral ischemia in early clinical head injury. J Cereb Blood Flow Metab 2004;24:202-211.

6. Oertel M, Boscardin WJ, Obrist WD, et al. Posttraumatic vasospasm: the epidemiology, severitu, and time couse of an underestimated phenomeno: a prospective study performed in 299 patients. $J$ Neurosurg 2005;103:812-824.

7. Dagal A, Lam AM. Cerebral blood flow and the injured brain: how should we monitor and manipulate it? Curr Opin Anaesthesiol 2011:24:131-137.

8. Dunn IF, Ellegala DB, FoxJF, Kim DH. Principles of cerebral oxygenation and blood flow in the neurological critical care unit. Neurocrit Care 2006; 4:77-82

9. Panerai RB. Cerebral autoregulation: from models to clinical applications. Cardiovasc Eng 2008;8:42-59.

10. Taccone FS, Castanares-Zapatero D, Peres-Bota D, Vincent JL, Berre $\mathrm{J}$, Melot C. Cerebral autoregulation is influenced by carbon dioxide levels in patients with septic shock. Neurocrit Care 2010;12:35-42.

11. Bratton SL, Chestnut RM, Ghajar J, et al. Guidelines for the management of severe traumatic brain injury. IX. Cerebral perfusion thresholds.J Neurotrauma 2007;24(Suppl):S59-S64.

12. Johnson U, Nilsson P, Ronne-Engström E, Howells T, Enblad P. Favorable outcome in traumatic brain injury patients with impaired cerebral pressure autoregulation when treated at low cerebral perfusion pressure levels. Neurosurgery 2011;68:714-722.

13. Filosa JA. Vascular tone and neurovascular coupling: considerations toward an improved in vitro model. Front Neuroenergetics 2010;16:1-8.

14. Sotero RC, Trujillo-Barreto NJ. Biophysical model for integrating neuronal activity, EEG, fMRI and metabolism. Neuroimage 2008;39:290-309.
15. Celotto AC, Capellini VK, Baldo CF, Dalio MB, Rodrigues AJ, Evora PRB. Effects of acid-base imbalance on vascular reactivity. Braz J Med Biol Res 2008;46:439-445.

16. Lindauer U,VogtJ, Schuh-Hofer S, DreierJP, Dirnagl U.Cerebrovascular vasodilation to extraluminal acidosis occurs via combined activation of ATP-sensitive and Ca2+-activated potassium channels. J Cereb Blood Flow Metab 2003;23:1227-1238.

17. Horiuchi T, Dietrich HH, Hongo K, Goto T, Dacey RG Jr. Role of endothelial nitric oxide and smooth muscle potassium channels in cerebral arteriolar dilation in response to acidosis. Stroke 2002;33:844-849.

18. Temes RE, Tessitore E, Schmidt JM, et al. Left ventricular dysfunction and cerebral infarction from vasospasm after subarachnoid hemorrhage. Neurocrit Care 2010;13:359-365.

19. Lindauer U, Kunz A, Schuh-Hofer S, Vogt J, Dreier JP, Dirnagl U. Nitric oxide from perivascular nerves modulates cerebral arterial $\mathrm{pH}$ reactivity. Am J Physiol Heart Circ Physiol 2001;281:1353-1363.

20. Bourdeaux C, Brown J. Sodium bicarbonate lowers intracranial pressure after traumatic brain injury. Neurocrit Care 2010;13:24-28.

21. Ferre S, Ciruela F, Borycz J, et al. Adenosine A1-A2A receptor heteromers: new targets for caffeine in the brain. Front Biosci 2008:13:2391-2399.

22. Gebremedhin D, Weinberger B, Lourim D, Harder DR. Adenosine can mediate its actions through generation of reactive oxygen species. $J$ Cereb Blood Flow Metab 2010;30:1777-1790.

23. Pelligrino DA, Xu HL, Vetri F. Caffeine and the control of cerebral hemodynamics. J Alzheimers Dis 2010;20 (Suppl) :S51-S62.

24. Thampatty BP, Sherwood PR, Gallek MJ, et al. Role of endothelin-1 in human aneurysmal subarachnoid hemorrhage: associations with vasospasm and delayed cerebral ischemia. Neurocrit Care 2011;15:19-27.

25. Wang ZP, Chen HS, Wang FX. Influence of plasma and cerebrospinal fluid levels of endothelin-1 and no in reducing cerebral vasospasm after subarachnoid hemorrhage during treatment with mild hypothermia, in a dog model. Cell Biochem Biophys 2011;61:137-143. Salonia R, Empey PE, Poloyac SM, et al. Endothelin-1 is increased in cerebrospinal fluid and associated with unfavorable outcomes in children after severe traumatic brain injury. J Neurotrauma 2010;27:1819-1825.

26. Fang YC, Wu JS, Chen JJ, et al. Induction of prostacyclin/PGI2 synthase expression after cerebral ischemia-reperfusion. J Cereb Blood Flow Metab 2006;26:491-501. 
27. Faraci FM, Heistad DD. Regulation of the cerebral circulation: role of endothelium and potassium channels. Physiol Rev 1998;78:53-97.

28. Koskinen LOD, Olivecrona M, Rodling-Wahlström M, Naredi S. Prostacyclin treatment normalises the MCA flow velocity in nimodipine-resistant cerebral vasospasm after aneurismal subarachnoid haemorrhage. Acta Neurochir 2009;151:595-599.

29. Naredi S, Olivecrona M, Lindgren C, Ostlund AL, Grände PO, Koskinen LO. An outcome study of severe traumatic head injury using the "Lund therapy" with low-dose prostacyclin. Acta Anaesthesiol Scand 2001;45:402-406.

30. Didion SP, Faraci FM. Effects of NADH and NADPH on superoxide levels and cerebral vascular tone. Am J Physiol Heart Circ Physiol 2002;282:H688-H695.

31. Faraci FM. Reactive oxygen species: influence on cerebral vascular tone.J Appl Physiol 2006;100:739-743.

32. Park L, Anrather J, Zhou P, Frys K, Wang G, ladecola C. Exogenous NADPH increases cerebral blood flow through NADPH oxidasedependent and -independent mechanisms. Arterioscler Thromb Vasc Biol 2004;24:1860-1865.

33. Kim DE, Suh YS, Lee MS, et al. Vascular NAD(P)H oxidase triggers delayed cerebral vasospasm after subarachnoid hemorrhage in rats. Stroke 2002;33:2687-2691.

34. Barkoudah E, Jaggar JH, Leffler CW. The permissive role of end othelial $\mathrm{NO}$ in CO-induced cerebrovascular dilation. Am J Physiol Heart Circ Physiol 2004;287:1459-1465.

35. Ishikawa M, Kajimura M, Adachi T, et al. Carbon monoxide from heme oxygenase-2 Is a tonic regulator against NO-dependent vasodilatation in the adult rat cerebral microcirculation. Circ Res 2005;97:104-114.

36. Koehler RC, Traystman RJ. Cerebrovascular effects of carbon monoxide. Antioxid Redox Signal 2002;4:279-290.

37. Toda N, Okamura T. The pharmacology of nitric oxide in the peripheral nervous system of blood vessels. Pharmacol Rev 2003;55:271-324.

38. Pluta RM. Delayed cerebral vasospasm and nitric oxide: review, new hypothesis, and proposed treatment. Pharmacol Ther 2005;105:23-56.

39. Toda N, Ayajiki K, Okamura T. Cerebral blood flow regulation by nitric oxide in neurological disorders. Can J Physiol Pharmacol 2009;87:581-594.

40. Dunn KM, Nelson MT. Potassium channels and neurovascular coupling. Circ J 2010;74:608-616.

41. Kwan AL, Lin CL, Wu CS, et al. Delayed administration of the K+ channel activator cromakalim attenuates cerebral vasospasm after experimental subarachnoid hemorrhage. Acta Neurochir (Wien) 2000;142:193-197.

42. Masamoto K, Tanishita K. Oxygen transport in brain tissue.J Biomech Eng 2009;131:74-82.

43. Johnston AJ, Steiner LA, Gupta AK, Menon DK. Cerebral oxygen vasoreactivity and cerebral tissue oxygen reactivity. $\mathrm{Br} J$ Anaesth 2003;90:774-786.

44. Cipolla MJ. The Cerebral Circulation. In: Granger DN, Granger J (Eds). San Rafael: Morgan \& Claypool Life Sciences series; 2010: 1-43.

45. Borgstrom L, Johannsson H, Siesjo BK. The influence of acute normovolemic anemia on cerebral blood flow and oxygen consumption of anesthetized rats. Acta Physiol Scand 1975;93:505-514.

46. Dineen NE, Brodie FG, Robinson TG, Panerai RB. Continuous estimates of dynamic cerebral autoregulation during transient hypocapnia and hypercapnia.J Appl Physiol 2010;108:604-613.

47. Curley G, Kavanagh BP, Laffey JG. Hypocapnia and the injured brain: more harm than benefit. Crit Care Med 2010;35:1348-1359.

48. Bor-Seng-Shu E, de Lima Oliveira M, Teixeira MJ. Traumatic brain injury and metabolism. J Neurosurg 2010;112:1351-1353.

49. Marcinkowska-Gapińska A, Kowal P. Comparative analysis of chosen hemorheological methods in a group of stroke patients. Clin Hemorheol Microcirc 2009;41:27-33.
50. Rebel A, Ulatowski JA, Kwansa H, Bucci E, Koehler RC. Cerebrovascular response to decreased hematocrit: effect of cell-free hemoglobin, plasma viscosity, and CO2. Am J Physiol Heart Circ Physiol 2003;285:1600-1608.

51. Tomiyama Y, Brian JE Jr, Todd MM. Plasma viscosity and cerebral blood flow. Am J Physiol Heart Circ Physiol 2000;279:1949-1954.

52. Le Roux PD. Anemia and transfusion after subarachnoid hemorrhage. Neurocrit Care 2011;15:342-353.

53. Sampson TR, Dhar R, Diringer MN, Fawtdoaash NC. Factors associated with the development of anemia after subarachnoid hemorrhage. Neurocrit Care 2010;12:4-9.

54. Naidech AM, Drescher J, Ault ML, Shaibani A, Batjer HH, Alberts MJ. Higher hemoglobin is associated with less cerebral infarction, poor outcome, and death after subarachnoid hemorrhage. Neurosurgery 2006;59:775-780.

55. Naidech AM, Jovanovic B, Wartenberg KE, et al. Higher hemoglobin is associated with improved outcome after subarachnoid hemorrhage. Crit Care Med 2007;35:2383-2389.

56. Malone DL, Dunne J, Tracy JK, Putnam AT, Scalea TM, Napolitano LM. Blood transfusion, independent of shock severity, is associated with worse outcome in trauma. J Trauma 2003;54:898-905.

57. Marik PE, Corwin HL. Efficacy of red blood cell transfusion in the critically ill: a systematic review of the literature. Crit Care Med 2008;36:2667-2674.

58. Hare GM, Mazer CD, Mak W, et al. Hemodilutional anemia is associated with increased cerebral neuronal nitric oxide synthase gene expression. J Appl Physiol 2003;94:2058-2067.

59. Bor-Seng-Shu E, Oliveira MD, Panerai RB, Teixeira MJ. Predicting symptomatic cerebral vasospasm after aneurysmal subarachnoid hemorrhage. Neurosurgery 2011;69:501-502.

60. McLaren AT, Marsden PA, Mazer CD, et al. Increased expression of hif-1alpha, nnos, and vegf in the cerebral cortex of anemic rats. Am J Physiol Regul Integr Comp Physiol 2007;292:403-414.

61. Smith MJ, Maggee S, Stiefel M, et al. Packed red blood cell transfusion increases local cerebral oxygenation. Crit Care Med 2005;33:1104-1108.

62. Kiyatkin EA. Brain temperature fluctuations during physiological and pathological conditions. Eur J Appl Physiol 2007;101:3-17.

63. Thompson HJ, Tkacs NC, Saatman KE, Raghupathi R, Mclntosh TK. Hyperthermia following traumatic brain injury: a critical evaluation. Neurobiol Dis 2003;12:163-173.

64. Forte LV, Peluso CM, Prandini MN, Godoy R, Rojas SS. Regional cooling for reducing brain temperature and intracranial pressure. Arq Neuropsiquiatr 2009;67:480-487.

65. Schubert GA, Poli S, Schilling L, Heiland S, Thomé C. Hypothermia reduces cytotoxic edema and metabolic alterations during the acute phase of massive SAH: a diffusion-weighted imaging and spectroscopy study in rats. J Neurotrauma 2008;25:841-852.

66. Török E, Klopotowski M, Trabold R, Thal SC, Plesnila N, Schöller K. Mild hypothermia (33 degrees $\mathrm{C}$ ) reduces intracranial hypertension and improves functional outcome after subarachnoid hemorrhage in rats. Neurosurgery 2009;65:352-359.

67. Polderman KH, Tjong Tjin Joe R, Peerdeman SM, Vandertop WP, Girbes AR. Effects of therapeutic hypothermia on intracranial pressure and outcome in patients with severe head injury. Intensive Care Med 2002;28:1563-1573.

68. Zhi D, Zhang S, Lin X. Study on therapeutic mechanism and clinical effect of mild hypothermia in patients with severe head injury. Surg Neurol 2003;59:381-385.

69. Jiang JY. Clinical study of mild hypothermia treatment for severe traumatic brain injury. J Neurotrauma 2009;26:399-406.

70. Hu K, Meng Y, Lei H, Zhang S. Differential changes of regional cerebral blood flow in two bat species during induced hypothermia measured by perfusion-weighted magnetic resonance imaging. J Comp Physiol B 2011;181:117-123. 
71. Bedell EA, DeWitt DS, Uchida T, Prough DS. Cerebral pressure autoregulation is intact and is not influenced by hypothermia after traumatic brain injury in rats. J Neurotrauma 2004;21:1212-1222.

72. Royl G, Füchtemeier M, Leithner C, et al. Hypothermia effects on neurovascular coupling and cerebral metabolic rate of oxygen. Neuroimage 2008;40:1523-1532.

73. Ogoh S, Brothers RM, Barnes Q, et al. The effect of changes in cardiac output on middle cerebral artery mean blood velocity at rest and during exercise. J Physiol 2005;569:697-704.

74. Van Lieshout JJ, Pott F, Madsen PL, Van Goudoever J, Secher NH. Muscletensing during standing: effects on cerebral tissue oxygenation and cerebral artery blood velocity. Stroke 2001;32:1546-1551.

75. Secher NH, Seifert T, Van Lieshout JJ. Cerebral blood flow and metabolism during exercise: implications for fatigue. J Appl Physiol 2008;104:306-314.

76. Koike A, Itoh $\mathrm{H}$, Oohara R, et al. Cerebral oxygenation during exercise in cardiac patients. Chest 2004;125:182-190.
77. Ainslie PN, Ogoh S. Regulation of cerebral blood flow in mammals during chronic hypoxia: a matter of balance. Exp Physiol 2010;95:251-262.

78. Lucas SJ, Burgess KR, Thomas KN, et al. Alterations in cerebral blood flow and cerebrovascular reactivity during 14 days at $5050 \mathrm{~m}$. J Physiol 2011;589:741-753.

79. Iwasaki K, Zhang R, Zuckerman JH, Ogawa Y, Hansen LH, Levine BD. Impaired dynamic cerebral autoregulation at extreme high altitude even after acclimatization. J Cereb Blood Flow Metab 2011;31:283-292.

80. Wilson $\mathrm{MH}$, Newman S, Imray $\mathrm{CH}$. The cerebral effects of ascent to high altitudes. Lancet Neurol 2009;8:175-191.

81. Bor-Seng-Shu E, Teixeira MJ. Brain vasospasm after head injury. J Neurosurg 2007;106:728-730.

82. Bor-Seng-Shu E, Hirsch R, Teixeira MJ, De Andrade AF, Marino R Jr. Cerebral hemodynamic changes gauged by transcranial Doppler ultrasonography in patients with posttraumatic brain swelling treated by surgical decompression. J Neurosurg 2006;104:93-100. 